The Journal of Society and Media, October 2020, Vol. 4(2) 262-278

https://journal.unesa.ac.id/index.php/jsm/index

E-ISSN 2580-1341 and P-ISSN 2721-0383

Accredited KEMENRISTEK/BRIN No.148/M/KPT/2020

DOI: 10.26740/jsm.v4n2.p262-278

\title{
Preservation of the Intellect: Developing Research Skills among IIUM Undergraduates
}

\section{Iyad M. Y. Eid ${ }^{*}$, Rohaiza Rokis ${ }^{2}$, Fatimah AlZahrah Bt Syed Hussien ${ }^{3}$, Szariannie Sulaiman ${ }^{4}$}

${ }^{1,2,3,4}$ Department of Sociology and Anthropology, Kulliyyah of Islamic Revealed

Knowledge and Human Sciences, International Islamic University Malaysia, Kuala

Lumpur, Malaysia

Street Gombak, 53100, Selangor, Malaysia

Email: iyad@iium.edu.my

Email: rohaiza@iium.edu.my

Email: fatimahalattas@iium.edu.my

Email: sza@iium.edu.my

\begin{abstract}
The purpose of this paper is to prove that undergraduates have the capacity to be engaged in conducting empirical research and generating knowledge. It discusses the outcomes of a recent research training programme offered to undergraduates at the International Islamic University Malaysia. The training programme was organized and conducted by the Department of Sociology and Anthropology. As of early 2020, about 700 undergraduates, including those studying at different departments at the Kulliyyah of Islamic Revealed Knowledge and Human Sciences (KIRKHS) have been trained. Working in teams, the undergraduates produced remarkable research projects presented in the form of written reports, oral presentations, and open discussions. To document these papers, the first social research collection book titled "Khalduniyyat" was submitted to the respective faculty, KIRKHS, for review and publication. This paper is based on a qualitative research approach, employing semi-structured interviews with fifteen academics who supervised or attended the training activities. Further, the paper reflects on the feedback provided by the trainees. The originality of this research paper is presented by showing how the programme explored and enhanced the intellectual capabilities of IIUM undergraduates, that resulted in the enhancement of their research skills equivalent to postgraduate level.
\end{abstract}

Keywords: research training, IIUM undergraduates, empirical, knowledge generation, Khalduniyyat

Paper type: Research paper

*Corresponding author: iyad@iium.edu.my

Submitted: 2020-05-12; Accepted: 2020-10-29; Published: 2020-10-30

Cite this document: Eid, Iyad M. Y., et al. (2020). Preservation of the Intellect: Developing Research Skills among IIUM Undergraduates. The Journal of Society and Media, 4(2), 262-278. doi: 10.26740/jsm.v4n2.p262-278 
Eid: Preservation of the Intellect:

Developing Research Skills among IIUM

Undergradu a tes

\section{INTRODUCTION}

Preservation of the intellect is one of the five dimensions of Maqasid alShari'ah, and the fourth goal of the Sustainable Development Goals (SDGs) which emphasizes on inclusive and equitable quality education and the promotion of lifelong learning opportunities for all. The establishment of the Kulliyyah of Islamic Revealed Knowledge and Human Sciences (KIRKHS) at the International Islamic University Malaysia (IIUM) in 1990 was on the drive to integrate between revealed knowledge and human sciences. Physically, KIRKHS is the biggest faculty at IIUM, with nine departments. The Department of Sociology and Anthropology works under its umbrella with the niche to lead the mission of studying the human society and its institutions, emphasizing on the expression of the Islamic perspective and Islamization of sociological knowledge (Zein and Noon 2013). A significant research examined the productivity of KIRKHS in terms of the number of theses for Master's and PhD degrees between the years 1990 and 2013. It found out that the Department of Usul al Fiqh led the list while the Department of Sociology and Anthropology produced the least and was located at the end of the list, one rank before the Department of History (El Meswai 2013).

In response to such intellectual gap, the Department of Sociology and Anthropology initiated a research training programme for hundreds of KIRKHS undergraduates. The students received intensive guidance and instruction on how to conduct a mini social research project and implement the fundamental research steps, including selecting the research topic, reviewing the literature, applying qualitative research approach, collecting and analyzing relevant data, writing and presenting findings. Since semester 2 of the academic session 2016/2017 until semester 2 of the academic session 2019/2020, the research training programme has been offered to almost 700 undergraduates, and the current paper reflects on the programme outcomes.

The academics at the Department of Sociology and Anthropology believe that it is necessary to locate undergraduates in fieldwork to observe social problems, investigate their causes and document the research experience (results) to inform the surrounding communities about structure of the research training programme. In fact, going to fieldwork to conduct social research sounded like a 
challenging task, especially because it was their first experience to apply research steps on the ground. Therefore, the students had to be motivated to perform this task by explaining their important role as researchers to discover the hidden factors or forces that have negative impacts on individuals and the social fabric of the society. According to C. Wright Mills, "sociological imagination works between the personal of the milieu and the public issues of social instruction (Mills 2015).

Moreover, the students were trained that the main rationale for going to fieldwork was to apply a theorical framework (sociological perspective) about the issue they decided to investigate. At this point, they developed a kind of understanding regarding the difference between the sociological perspective, which is based on rational thinking and evidence owning and the personal point of view which relies on common sense.

To accomplish the research task more efficiently and obtain productive outcomes, the programme was implemented on the principle of teamwork by dividing the students into groups of four as cooperative work would promote commitment and patience among team members and produce effective work within the allocated time. In addition, it could steer the students' intellectual potentials through sharing creative ideas and discussing their arguments.

Students benefit from opportunities to collaborate on group projects especially throughout their undergraduate careers (Colbeck, Campbell and Bjorklund 2000) Teamwork is a soft skill that carries numerous advantages. It enhances creative and critical thinking and ideas. It increases knowledge in the subject matter being discussed, boosts the quality of learning and improves the quality of workmanship (Sulaiman et al. 2016). Team rules put things in order and give every teammate a voice within team meetings. As a result, stress and conflict are kept to the minimum at least for the things that have been discussed and agreed upon earlier (Asonitou 2013). At the psychological level, working with teams increases students' self-esteem as they develop more positive feelings than working individually (Salvin 1982). It also results in mature communication, accountable interdependence and psychological safety because team members have a common purpose and have a clear understanding of their role (Ulloa and Adams 2004). Teamwork may involve working with people for the first time and 
Eid: Preservation of the Intellect:

Developing Research Skills among IIUM

Undergradu a tes

this creates a positive learning experience and prepares for a wider circle of cooperation with colleagues in the future career (Wilson, Ho and Brookes 2017).

The students received step by step instructions on the research process, including determining the research topic, reviewing the literature, identifying the sample, constructing interview questions, collecting relevant data, analyzing data and presenting results. They also received guidance on how to formulate research hypotheses, modify, refute or confirm them at the end of the research process. The following sections discuss how the students conducted the mini research project and performed written and oral presentation. Figure 1 shows the sequence of the project implementation.

\section{Figure 1}

\section{Steps of the Research Project}

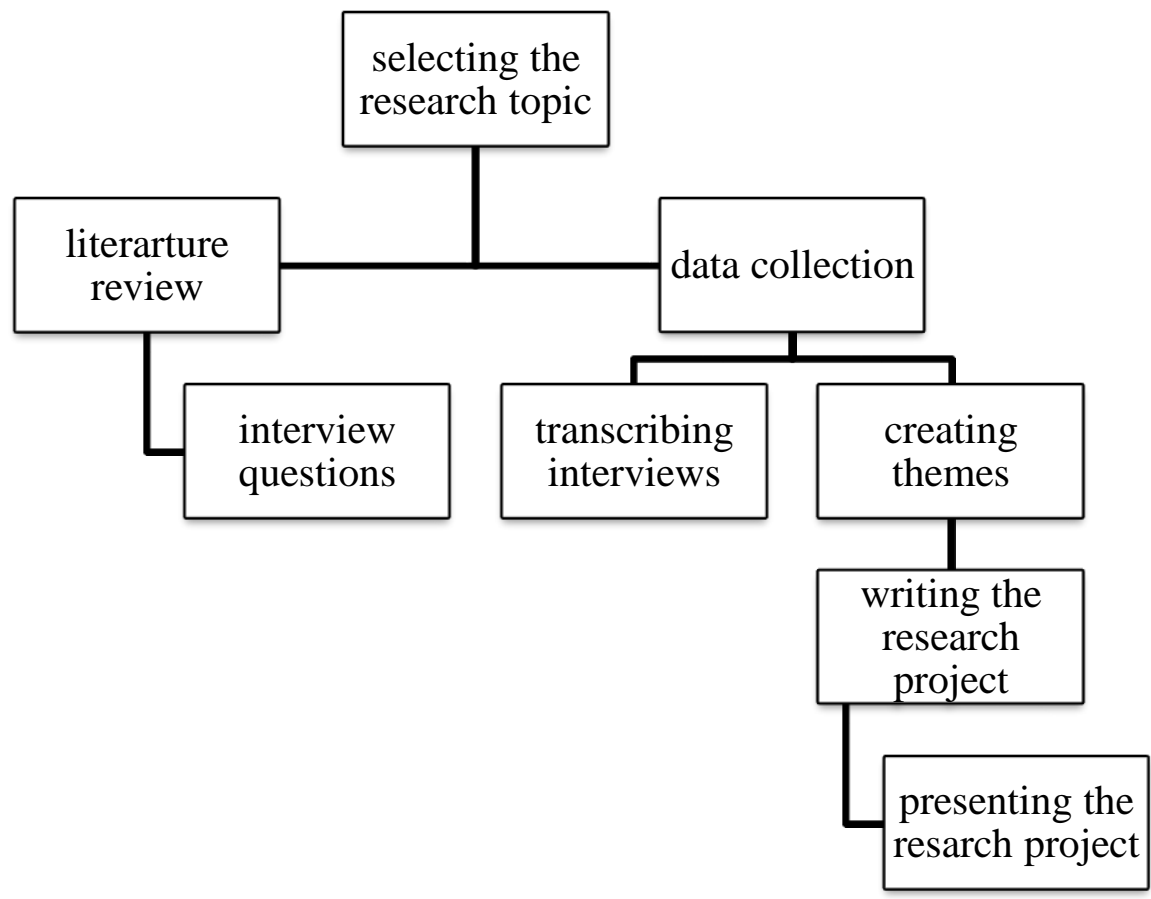

Selecting a researchable topic to find the appropriate sample for data collection was the most essential start. The students received good trainings on how to apply qualitative research approach to investigate one of the social issues related to certain sociological themes such as religion, urbanism, race and ethnicity, health, environment, family and others. One of the most prominent features of the programme was instructing the undergraduate students how to review existing literature to build up the theoretical framework of the research 
project. They were required to search for recent scholarly articles, using online database. As the research project was based on teamwork, every team member was required to review four articles and paraphrase the objectives, methodology and findings. Then the group combined the reviewed literature to formulate research questions to collect data, whether from non-governmental organisations (NGOs) or public places.

\section{METHOD}

The task of collecting data constituted the beginning of field entry where the students interacted with research participants. For more adequate accomplishment, teammates were trained to play specific roles during this step to ensure systematic data collection. They conducted in-depth semi structured interviews with all the participants, using the interview questions they formulated after reviewing previous studies (Slavin 1982). While one teammate interviewed the participants, the second took field notes, observing the facial and body gestures of the interviewees, the third recorded the interviews and the fourth took snapshots of the teammates and participants in the research location as proof of genuine research work.

Most of the research projects were based on a sample of four participants which met all the sample characteristics such as illegal workers, single mothers, transgender, HIV patients, etc. For flexible implementation and personal safety, the students obtained a permission letter from the Department of Sociology and Anthropology to collect primary data.

Following data collection, the students reached the stage to deal with the data they obtained in the fieldwork. They transcribed the interviews and arranged the data, showing deep understanding of the social issues they investigated. They compared between interview responses and highlighted similarities and differences to create meanings and classify themes based on the literature review. They showed creativity in describing research sites and analyzing the body language of the participants. Finally, the students reached the most significant stage of presenting the details of the research project in a written form. They produced an organized piece of writing, showing the abstract, objectives of the study, methodology, findings and conclusion. They also modified the suggested 
titles to fit the research content and included the references at the end of the paper, applying APA style.

Writing is a skill which is important to develop at the stage of graduate studies, and it is even more important for success after graduation (Bridgeman and Carlson 1984). Effective writing practices are positively associated with students' practical competence, general education learning and personal and social development (Anderson et al. 2015). When writing reflectively about an experience, students become aware that there is a thinking process underlying such type of writing to justify actions, solve problems, interpret results or synthesize ideas; as a result, their critical thinking improves (Bouanani 2015). According to Sanchez and Lewis, writing shapes thinking, and structured writing tasks contribute to increasing knowledge in content material (Sanchez and Lewis 2014). Besides mastering the content, written language supports the more complex kind of reasoning that is necessary for successful performance in our complex technological and information-based culture (Langer and Applebee 1987). Throughout writing, students could come up with good points or expressions. This is the stage where they are expected to perfect their work and make their personal contribution (Rao 2007).

Besides writing the research, the students were trained to perform a threeminute presentation to inform about their respective work. Following the same team divisions, the students impressed the attendants while showing the results of research projects. For effective performance, every teammate had a role to play within 45 seconds. The first student introduced the objective of the study, the second briefly presented the literature, the third explained methodology and the fourth presented the research results. Additionally, the group showed relevant photos mainly taken in the research site.

Presentation is a student-centred meaningful activity which creates active learners (Brooks and Wilson 2014). It provides university students with unique organizational skills for their studies as well as future career. They become aware of their personal responsibilities as learners rather than "sinks" for facts and opinions provided by the lecturer (Fallows and Steven 2005). They get the chance to show creativity when they respond to different perspectives and ways of looking at problems. Being able to communicate effectively is the challenge of the 
current global job market (Živković 2014). Imam and Alalyani also suggested that the present rapidly changing and competitive world requires young people who are flexible, active, innovative and creative in problem solving and decision making through effective communication of ideas (Imam and Alalyani 2017). Building employability skills like presentation has become a significant educational goal (Alshare and Hindi 2004). At the linguistic level, when students speak with confidence in front of others, they develop their verbal proficiency (Al-Hebaish 2012). Oral presentation also exposes the learners to the opportunity of learning new vocabulary, correcting pronunciation and developing their speaking and listening skills (Zitouni 2013).

The programme outcomes to share with the university community the research-based learning experience, the programme organizers initiated an exhibition inside IIUM Dar al-Hikmah Library where the students showed pictures of the research and shared their experiences with the library's visitors. Needless to say, discussions and sharing ideas with undergraduates, postgraduates and academics from different faculties boosted their self-confidence and reinforced what they had learned in the fieldwork. Apart from ordinary evaluation system, the programme received positive feedback from IIUM community. The following section presents the highlights.

Dr. Rohaiza Rokis, one of the project organizers, showed determination to overcome all possible challenges that could hinder the success of the programme. She always expressed her optimistic view that it would become a comprehensive and permanent project, contributing to the development of the department in the future. She greatly supported the idea of publishing a video report about the programme on YouTube. Surprisingly, the video has had more than two thousand views and still receives positive comments praising such academic achievement.

During the interview, Dr. Rohaiza remarked,

"Our students have the capacity under the good guidance to do a very systematic and rigorous research within a limited time (one semester) they managed to present their work based on the data collection they have done. Quiet surprisingly, they managed to do it in a very confident manner and the output of their research is very great. We trained students to be disciplined, to be their own as well as have teamwork efforts. In the end, it not just getting theoretical aspects but most importantly the practical aspects to be good workers in the future". 
Similarly, the course coordinator, Dr. Nor Aisah Areff had the following view,

"This learning context is a good exposure for the students to understand human behaviours and social interactions. Apart from having a lecture in the class, they are asked to be involved in real life. They conduct research to address different social issues related to religion, culture, health, race and ethnicity and highlight their impact on the society. They have promoted the sense of commitment within teamwork and acquired fundamental skills related to research process".

The accounts highlighted above greatly reflected the capability of IIUM undergraduate students to manage basic research steps, regardless to their field of study. The feedback also emphasized that the programme has created new knowledge by implementing social research, promoting equal participation among students. We conclude from this evaluation that the research programme can be implemented on a regular basis. The programme organizers also interviewed academics and IIUM staff who visited the exhibition and expressed their views regarding students' remarkable capability to present and communicate their research results.

Dr. Anwar Al-Abbasi from the Kulliyyah of Economics pointed out,

"The project was very interesting. It helped the students show their ideas and implement what they studied in the class. During my visit to the exhibition, I discussed with them how they conducted the research for their selected topics. I found that some of them practised conducting semi-structured interviews. Also, their discussion about findings was very systematic and interesting. I wish that all the departments in IIUM follow this style of learning".

During his academic visit to the Department of Sociology and Anthropology, IIUM, Professor Dr. Sari Hanafi, the Head of the Department of Sociology in the American University of Beirut (AUB), who was also the President of the International Sociological Association (ISA), remarked about the programme and said,

"It is extremely important to have courses with concrete methods inside which require students to engage with the society to study contemporary issues. The programme is a big asset to the Department of Sociology and Anthropology, IIUM. The earlier students start, the 
more efficient they build up their concrete skills, especially in the final year project (FYP)".

Dr. Kamola Bayram, form the Department of Islamic Economics and Finance at Koto Karatay University in Turkey, commented,

"The project exhibition is uniquely impressing. It pushed students to the field of interactive learning. I was surprised to see undergraduate students of ages ranging between 19-23 years interviewed people with real social problems like HIV, refuge, single mothers, homelessness, transgender, showing academic skills in reporting the findings which the postgraduate students face challenges to achieve. The project promotes IIUM as a research university, and with this learning experience, I think, students will excel in their masters' studies".

The interview responses from IIUM academics and others confirmed that the implementation of the programme was systematic and professional. It encouraged the programme's organizers to train the students on doing more advanced research methods. There were also interviews sessions conducted with the students who were involved in the research training programme. They expressed their perspectives regarding the new learning experiences and the research skills they practised. Ilhami, a student from the Department of Communication, talked about the impact of different modes of communication involved in the programme on boosting her self-confidence and motivation. She remarked,

"The project enhanced my research skills which were very new to me. It helped me boost my confidence to share the knowledge that I didn't know before. As a student, I am used to receiving knowledge by traditional teaching approach; attending classes, doing some reading, assignments, exams, ... etc. This course encouraged me to go outdoors to meet participants and collect data. I really felt that I was a real researcher".

Andrew, studying at the Department of Political Science, commented,

"This programme took me beyond my expectations. I never thought that a training course would teach me all these skills, especially for students like me not studying at department of sociology. I learned how to interview participants, listen to their stories and observe their gestures. I have always thought that masters' degree is quiet challenging, but now I am optimistic to pursue my masters".

At this point, we conclude that the research training programme was a unique learning experience. It developed the students' research skills which are 
worldly recommended to substitute the traditional learning style based on memorization. The following discussion presents how the programme meets one of Maqasid al-Shriah (Esen 2015) and the fourth goal of sustainable development which are considered as part of IIUM university's mission.

\section{RESULTS AND DISCUSSION}

By presenting the research-based learning experience, one may ask about the relevance of this account to Maqasid al-Sharia. There are the common misperceptions that Maqasid al-Sharia strictly belong to the fields of Fiqh and Usul al-Din, and scholars specialized in these domains are the only ones who are able to tackle them. For this, the reader needs to understand that Maqasid alSharia are also an approach adopted by the Muslim intellectuals who seek to provide protection for the human society in various areas of life within five interrelated necessities; protection of self, protection of faith, protection of wealth, protection of intellect and protection of progeny.

Humans beings are intellectual beings in that they need to develop their knowledge and therefore serve humankinds and fulfil development and well-being for themselves and societies surrounding them. Yet, the intellect cannot accomplish these ends without being based on and guided by faith. Islam considers that revelation and reason work side by side in the life of Muslims as the former provides the correct direction to the latter. Likewise, the intellect supports one's faith to realize Maqasid al-Sharia in times of social or economic changes. Thus, the interrelated roles of faith and intellect strengthen them to promote human development (Chapra 2008).

In Islam, religious obligations are only assigned to people who have mental capabilities and do not suffer from any biological dysfunction (Esen 2015). While the Quran refers that not all Muslims have the ability to be knowledgeable and produce knowledge, it assigns such intellectual responsibility to a group of members from the whole society, and their mission is to seek knowledge to save their society (Ashur 1982). Allah S.W.T says, "Of every troop of them, a party only should go forth," (Quran 9: 122). 
The intellect is the quality which makes humans have rights and duties as well as carry out responsibilities (Esen 2015). More importantly, it is the source of knowledge and wisdom (Ghazalli 2005) which humans are required to share (Esen 2015). It has to be protected biologically and intellectually. The biological needs include healthy food and drinks while the intellectual necessities include reading and thinking. According to Chapra (2008), the intellect can be enriched by obtaining high quality religious and science education, involving in text interpretation, doing research, exercising freedom of thought and expression and producing creative work (Khan 2011).

The research programme was prepared to steer the students' intellectual potentials to benefit the human society in various ways. Basically, it was implemented within the necessity of promoting the intellect as proposed by Maqasid al-Sharia. It created a kind of awareness about fulfilling the inevitable role of khilafa which is commonly thought to be belonging to specific group of people rather than the whole humanity. Learning and getting knowledge are the basic requirements of khilafah and both promote intellectual capabilities. The programme's content met these requirements and equipped the students with fundamental thinking skills. Rational thinking is one of the necessities that control irrational attitudes, create balance and establish system in the society. This is how the Quran deals with the human intellect, requesting man to look, think, learn and read (Ashur 1985). Allah S.W.T says, "Say: Are those who know equal to those who know not?" (Quran 39: 9). Thus, within Maqasid al-Sharia learning and practicing science are a kind of obligation among Muslims. They have to acquire professional skills to guide their steps, protect the human society and improve their life without waiting for any worldly rewards.

Sustainable Development Goals (SDGs) are another approach which focuses on quality of education and recommends individuals to acquire knowledge for developing the life of humans in terms of human rights, gender equality, promotion of the culture of peace and non-violence, global citizenship, etc. It would be relevant to remark that SDGs are originally proposed to address humanitarian issues related to western societies, and most of the outcomes of the solutions suggested for developing the Muslim world are built on the western style (Al-Faruqi 1987). For this reason, Muslims must revive their own Islamic educational style on the basis of their values, principles and culture and in 
Eid: Preservation of the Intellect:

Developing Research Skills among IIUM

Undergradu a tes

accordance to Maqasid al-Sharia to find solutions to their own crises and develop their countries. Such design is supposed to be opposite to the western SDGs because the Islamic style relies on the principle of Tawhid that introduces man as a khalifa, responsible for bringing positive changes for humanity in the worldly life as well the life-after. Allah S.W.T. says, "And remember when your Lord said to the angels: "Verily, I am going to place (mankind) generations after generations on earth.” (Quran 1:30).

The target students in the programme were taught that serving the society is not just a temporal materialistic task, but rather it is based on a divine order. If students do not know about the natural composition of the human society, they will not be able to observe social changes whether at the individual or society level, in turn, they will not develop their intellect. In this sense, missing to fulfil the characteristic of hifz alaql (preserving the intellect) might lead to losing hifz aldin (preserving religion). Engaging in fieldwork research preserved the students' intellect by practicing various fundamental tasks; observing a research problem, collecting data, writing, presenting and finally publishing the research.

Applying reason to observe the surroundings is a task emphasized by the shariah. The research project substantially activated the students' intellect to watch the participants, listen to their conversations and narratives, document and analyze their actions. Needless to say, these processes developed their rational thinking to seek interpretations regarding cause and effect to produce new knowledge. The research-based learning opportunity also enhanced their critical thinking to write interview questions, collect comprehensive data, establish connections between ideas and provide qualitative analysis.

Writing the details of the research is normally a challenge even for professional writers. However, the cohort of the present research training programme obtained basic writing skills, and this was reflected in their clear and organized thinking and full understanding of the research problem. Thus, we can say that the programme transformed the mental abilities of students ranging between 20-24 years by training them how to make comparisons between the reviewed literature and collected data to highlight and explain facts.

Presenting the content of the research within three minutes was the most challenging task. It sharpened the students' communication skills by using 
appropriate, clear and engaging language in front of the audience in the presentation hall. During the exhibition at the library, they demonstrated great confidence to talk freely and publicly about the research findings and the challenges they faced during the project. The proficiency in communicating ideas showed improved cognitive abilities in determining the information to be presented. Showing focused pictures also reflected their creative thinking skills in enriching the audience understanding of the brief information presented. Thus, the programme had the contribution of enhancing humanity among the students by looking at the 'vulnerable' other; for example, the refugees, the homeless, the jobless, online gamers, teenage smokers, the transgender, etc. In other words, the programme contributed in making "the person" as recommended by the university rector during his participation in a National Forum on SDG.

Finally, the most remarkable fruit of the training programme was the production of a book titled "Khaldunniat" which included a collection of the students' research projects. The book greatly reflects quality research skills which the students acquired. This added skill is expected to take them to the level of publishing in academic journals. Further, it will pave the way to the programme organizers to establish professional connections and collaborations with other academic institutions to develop the programme whether in Malaysia or abroad.

The successful experience of training students on research could be shared and duplicated to other faculties and departments in IIUM and other universities whether Islamic and non-Islamic in and beyond Malaysia. In fact, being an IIUM student is not an ordinary educational journey. Students do not merely attend lectures, move from one semester to another and finally graduate with keen wishes to join workforce and secure a permanent financial source. Instead, they must have life-long commitment towards the Ummah; therefore, they need to have the sincere intention to fulfil the role of khilafa by meeting the call 'Every Muslim must be a scientist'. To achieve such duty in a sound way, they must understand the message articulated by the IIUM Rector, Professor Dato Dzulkifli Abdul Razak, when he remarked,

"Without generating knowledge, the university is dead. We need to generate it by research. To bring a new knowledge is to bring new concepts and ideas. The concept of research university is that every student and staff member must do research, including the people who 
Eid: Preservation of the Intellect:

Developing Research Skills among IIUM

Undergradu a tes

sweep the road because they must know the new technology in terms of sweeping to make their work better. We must know what is new. All of us must get involved to generate knowledge".

\section{CONCLUSION}

The supreme goal of education is to serve and develop human communities. However, undergraduates still lack necessary learning skills such as conducting research. There is a common misconception that developing research skills to conduct empirical research by going to fieldwork to collect primary data and produce a complete research paper are in the domain of the postgraduates while the undergraduates remain stuck in receiving knowledge and submitting theoretical assignments. IIUM, as an Islamic university with an Islamic vision, leads the initiative to develop the Ummah. It has the mission to integrate between the contributions of contemporary and revealed knowledge. In this way, Muslims do not start from the scratch but continue from the point where others finished. This paper reflected to what extent the Department of Sociology and Anthropology is accountable for carrying out duties towards the students who represent the hope of the entire Ummah by training them to be researchers to discover social illnesses affecting the wellbeing of individuals and societies. So far, about 700 undergraduates, studying at different departments at the Kulliyyah of Islamic Revealed Knowledge and Human Sciences (IRKHS) have been trained. They were required to go to fieldwork and conduct mini social research projects. Working on the basis of teams, the undergraduates produced research projects presented in the form of written reports, oral presentations and open discussions. To document intellectual accomplishments, the first social research collection book titled "Khalduniyyat" was compiled and submitted to KIRKHS for review and publication. This paper proposed that under good training and guidance, the undergraduates studying humanities in IIUM could acquire research skills including selecting researchable social problems, reviewing the literature, collecting data and writing and presenting results. They were trained how to be active partners in generating knowledge rather than being traditional recipients. 
276 | The Journal of Society and Media 4(2)

Further, the new learning experience familiarized them with the essential components of academic journal articles. 


\section{REFERENCES}

El Meswai, Mohamed El-Tahir. 2013. "Promoting Islam through Research and Publication: Theses and Journals." In IIUM: The Premier Global Islamic University, edited by Zaleha Kamaruddin and Abdul Rashid Moten, 139151. Kuala Lumpur: IIUM Press.

Al-Faruqi, Ismail. 1987. Islamization of Knowledge: General Principles and Work Plan. Herndon: International Institute of Islamic Thought.

Al-Hebaish, Safaa Mohammad. 2012. "The Correlation between General SelfConfidence and Academic Achievement in the Oral Presentation Course." Theory and Practice in Language Studies 2(1): 60-65.

Alshare, Khaled and Nitham M. Hindi. 2004. "The Importance of Presentation Skills in the Classroom: Students and Instructors Perspectives." Journal of Computing Sciences in Colleges 19(4): 6-15.

Anderson, Paul, Chris M. Anson, Robert M. Gonyea, and Charles Paine. 2015. "The Contributions of Writing to Learning and Development: Results from a Large-Scale Multi-Institutional Study." Research in the Teaching of English 50(2): 199-235.

Asonitou, Sofia. 2013. "Improving Teamwork and Communication Skills through an Action Research Project." Paper presented at WSEAS Conference, Special Session: New Trends and Technologies for Marketing, Management, Economics and Information Processing II. January 2013, Athens, Greece.

Bouanani, Nafiaa. 2015. "Enhancing Critical Thinking Skills through Reflective Writing Intervention among Business College Students." IOSR Journal of Research \& Method in Education 5(1): 50-55.

Bridgeman, Brent, and Sybil B. Carlson. 1984. "Survey of Academic Writing Tasks.” Written Communication 1(2): 247-280.

Brooks, Gavin, and John Wilson. 2014. "Using Oral Presentations to Improve Students' English Language Skills.” Humanities Review Journal 19(1): 199-212.

Chapra, M. Umer. 2008. The Islamic Vision of Development in the Light of Maqāsid Al-Sharì'ah. Jeddah: Islamic Research and Training Institute.

Colbeck, Carol L., Susan E. Campbell, Stefani A. Bjorklund. 2000. "Grouping in the Dark: What College Students Learn from Group Projects." Journal of Higher Education 71 (3): 60-83. 
Esen, M. Fevzi. 2015. "A Statistical Framework on Identification of Maqasid Al-Shariah Variables for Socio-Economic Development Index," Journal of Business Studies Quarterly 7(1): 107-124.

Fallows, Stephen, and Christine Steven. 2000. "Building Employability Skills into the Higher Education Curriculum: A University-Wide Initiative." Education+ training 42(2): 75-83.

Ghazalli, Imam. 2005. Ihya 'a Ulum Alddin. Beirut: Dar Ibn Hazm.

Ashur, Tahir Ibn. 1985. The Origins of the Social System in Islam. Algeria: The National Establishment for Book.

Imam, Syed Ali and Mesheil Alalyani. 2017. "Study of Significance of Oral Presentation and its Impacts on Students of College of Applied Medical Sciences, Khamis Mushait, King Khalid University, Kingdom of Saudi Arabia- A Pilot Study." Imperial Journal of Interdisciplinary Research 3(4): 1438- 1442.

Khan, M. M and Al-Hilali, M. T. 2011. Interpretation of the Meaning of the Noble Quran in the English Language. Riyadh: Darussalam

Langer, Judith A. and Arthur N. Applebee. 1987. How Writing Shapes Thinking: A Study of Teaching and Learning. Washington: National Council of Teachers of English.

Mills, C. Wright. 2000. The Sociological Imagination. New York: Oxford.

Sulaiman, Mashitah, Zawiah Binti Hj. Mat, Faridah Binti Che Husain, Adibah Sulaiman Mohamad, Mohd Azmir Mohd Nizah and Latifah Abdul Latiff. 2016. "The Impact of Teamwork skills on Students in Malaysian Public Universities." Paper presented at International Conference on Humanities and Technology, 17-18 August, Melaka, Malaysia

Rao, Zhenhui. 2007. "Training in Brainstorming and Developing Writing Skills." ELT Journal 61(2): 100-106.

Sanchez, Bernice and Katie D. Lewis. 2014. "Writing Shapes Thinking: Investigative Study of Preservice Teachers Reading, Writing to Learn, and Critical Thinking." Texas Journal of Literacy Education 2(1): 55-68.

Slavin, Robert E. 1982. Cooperative Learning: Student Teams. What Research Says to the Teacher. 1982. Washington D. C.: National Education Association Professional Library.

Ulloa, Bianey C. Ruiz and Stephanie G. Adams. 2004. "Attitude toward Teamwork and Effective Teaming." Team Performance Management 10(7-8): 145-151. 
Wilson, Laura, Susie Ho and Rowan H. Brookes. 2018. "Student Perceptions of Teamwork within Assessment Tasks in Undergraduate Science Degrees." Assessment \& Evaluation in Higher Education 43(5): 786-799.

Zein, Ibrahim and Hazizan Md. Noon. 2013. "Relevantisation and Islamization: The Experience of the Kulliyyah of Islamic Reveled Knowledge and Human Sciences." Pp. 171-180 in IIUM: The Premier Global Islamic University, edited by Kamaruddin, Zaleha and, Abdul Rashid Moten: Kuala Lumpur: IIUM Press.

Zitouni, Nadia. 2013. "The Use of Students' Oral Presentations in Enhancing Speaking Skill in the English Language Classrooms: The Case Study of Second Year Students at the Department of English in Biskra University." master dissertation, Mohamed Kheider University of Biskra, Algeria. Retrieved from http://archives.univbiskra.dz/bitstream/123456789/4777/1/The\%20Use\%20of\%20Students\%2 7\%200ral\%20Presentation\%20in\%20Enhancing\%20Speaking\%20Skill.p df

Živković, Slađana. 2014. "The Importance of Oral Presentations for University Students." Mediterranean Journal of Social Sciences, 5(19): 468-468. 